\title{
THE MODELS EVALUATING COURIER
}

\section{AND MESSENGER COMPANIES IN POLAND}

\author{
EWA CHODAKOWSKA, JOANICJUSZ NAZARKO
}

\begin{abstract}
A B S T R A C T
Data Envelopment Analysis (DEA) is a well-established, popular, and often used method for efficiency evaluation of units from all sector, both commercial and nonprofit organisations, of any scale of operations. Network DEA models are a relatively recent approach used to examine the efficiency of decision-making units (DMUs) having an internal structure of sub-processes. The article presents the concept of DEA network models in estimating the efficiency of courier and messenger companies with relations to their business clients. The considerations are supported by an example of data concerning leaders from the sector of couriers and messengers in Poland and one of the biggest and most popular online stores. The results are compared with the traditional DEA approach. In addition, to measure reliability for DEA scores, the jackknife procedure was performed. The author proves the usefulness of network DEA as a research and management tool.
\end{abstract}

KEY WORDS

courier and messenger companies, network DEA, efficiency, evaluation

DOI: 10.1515/emj-2016-0032
Corresponding author:

Ewa Chodakowska

Faculty of Management, International China and Central-Eastern Europe Institute of Logistics and Service

Science, Poland

e-mail: e.chodakowska@pb.edu.pl

Joanicjusz Nazarko

Bialystok University of Technology, Faculty of Management, International China and Central-Eastern Europe Institute of Logistics and Service Science, Poland

e-mail: j.nazarko@pb.edu.pl

\section{INTRODUCTION}

Increased market competition, changing customer requirements and the provisions for the management of product lifecycle mean that many companies are searching for new operational models. To a great extent, this process applies to logistics systems in companies. A growing number of firms focus on their core competency and begin to outsource the logistics activities, contributing to the increasing popularity of third-party logistics (3PL) and fourth-party logistics (4PL) services. It is worth emphasizing that in many cases the operational efficiency of the chosen logistics system can be the factor that determines the competitiveness of a company. Data Envelopment Analysis (DEA), since its introduction, has become widely used for measuring the efficiency of logistics provid- 
ers as well as whole logistics systems. The following section of the article provides some literature that supports this statement. The article focuses on the efficiency of courier and messenger companies. A case study includes the courier market in Poland.

\section{LITERATURE REVIEW}

Based on a literature review on the subject of the application of the DEA method in logistics, it can be noticed that the majority of the publications focused on the comparative efficiency of enterprises providing logistics services. Among others, DEA was used for benchmarking of the operational efficiency of major 3PLs in the USA (Min \& Joo, 2006). The proposed approach allowed to evaluate the prioritization of the use of financial resources and identify the potential cause for inefficiency. According to the researchers, DEA measures the operational efficiency better than traditional financial ratios, such as return on investments or assets.

There were also assessments of substantial components of supply chains and logistics operations. The work by Johnson \& Mcginnis (2011) evaluating warehouses can serve as an example. According to the researchers, financial indicators, for example, revenue related to cost, are not fully appropriate because warehouses function to support the supply chain rather than generate revenue. Moreover, the settings and the general economic conditions of the warehouse owners have the major impact on the costs of the resources used by each warehouse. Researchers reviewed the literature on warehousing performance assessment and proposed the two-stage method that consists of estimating the efficiency in the first stage using DEA and identifying contextual variables correlated with high efficiency in the second stage using a regression model. The data were collected via the iDEAs-W website (http://ise.tamu.edu/ideas/). DEA found to be a useful method to evaluate both individual warehouses and groups of warehouses and to identify the operational policies, design characteristics and attributes correlated with technical efficiency.

Another example is a comparative analysis of the efficiency of Chinese and Korean major container terminals from the list of world top container ports published in $2010 \mathrm{Lu} \&$ Wang (2012). According to the work, DEA provided a more appropriate benchmark with insights into resource allocation and optimization of the operating efficiency, helped to identify the returns to scale and the potential areas of improvement for inefficient terminals. Empirical results derived from DEA revealed that substantial waste exists in the production processes in the world's leading container terminals.

In addition to publications that treat companies or logistics departments as 'black boxes' where inputs are transformed into outputs, recent trends tend towards the analysis that looks inside the organisations using the network DEA approach. The network DEA considers the existence of several stages, each of which consumes its own set of inputs and produces its own set of outputs, in addition to consuming and producing intermediate products. One of the first works introducing and popularizing the network methodology were Färe \& Grosskopf (2000) and Lewis \& Sexton (2004). The first paper provided the general framework of the network DEA model. Lewis \& Sexton (2004) presented some theoretical properties of the network DEA model and applied it to major league baseball. Kao (2014) conducted a comprehensive review of studies related to network DEA with regard to both the models and structures examined. Cook \& Zhu (2014) provided a complete source for the state-of-the-art DEA modelling the internal structures and network DEA.

In the field of logistics, the advantages of network DEA were used in attempts to measure the performance of supply chains. Due to the network nature of many supply chains, DEA seems to be a suitable tool for the analysis of comprehensive supply chains.

Zhu (2003) presented a DEA-based supply chain model with four echelons: suppliers, manufacturers, distributors, and retailers to measure the efficiency of both the supply chain and its members. A provided numerical example in Microsoft Excel yielded a set of optimal values of the intermediate performance measures and indicated that two supply chains might have different input-output mix, and both might be efficient.

Liang et al. (2006) developed several DEA-based approaches for characterizing and measuring supply chain efficiency when intermediate measures are incorporated into the performance evaluation. The models were illustrated in a hypothetical seller-buyer supply chain context when the relationship between the seller and buyer is treated as leader-follower or is cooperative.

Chen et al. (2006) investigated the efficiency game between two supply chain members: a supplier and a manufacturer. They developed two efficiency functions for the supplier and the manufacturer and 
showed that numerous Nash equilibriums efficiency plans exist for the supplier and the manufacturer.

Chen \& Yan (2011) established the network DEA model for the efficiency evaluation of two stage supplier-manufacturer supply chain. Three theoretical network DEA models were introduced to the concept of centralised, decentralised and mixed organisation mechanisms. In a centralised control mechanism, the supply chain is supervised by a single decision maker who can arrange the supplier and manufacturer operations to maximise the whole supply chain efficiency. In a decentralised organisation, each of the division has its own missions and strategies. The conducted analysis proved that only for the centralised control mechanism it is possible to take the internal structure of supply chain as a 'black box' when evaluating the performance.

Wong \& Wong (2007) adopted two DEA models (technical efficiency model and cost efficiency model) to measure internal supply chain performance. The output and input variables used for analysis were respectively revenue, on-time delivery rate and cost, internal manufacturing capacity, and cycle time. The concept integrates elements of the supply chain and evaluates them as one system. However, in contrast to the above-mentioned works, the proposed DEA-based approach was confirmed by a real data set from companies operating in the semiconductor sector of Malaysia. According to the researchers, the information obtained from the DEA models could help managers identify the inefficient operations and take the right remedial actions for continuous improvement.

The supply chain efficiency measured by the application of DEA was also presented by Mishra (2012). A case study included 29 enterprises from the pharmaceutical industry of India. Eight inputs (internal manufacturing capacity, supply chain cost, working capital, invested capital, the number of employees, wages to workers, material consumed and fuels consumed) and two outputs (net value added and net income) were considered. The obtained results indicated the scope for improvement of the pharmaceutical companies.

Momeni et al. (2014) took into account that the input and output data in real-world problems are often imprecise or ambiguous and proposed a fuzzy network slack-based DEA model for evaluating supply chain networks with imprecise data and reverse logistics. A case-study was presented to demonstrate the applicability of the proposed model in evaluating the procedures of a supply chain in the semiconductor industry.

More awareness of the environmental damage caused by human activities, and increased attention towards the environment, resulted in the development of a methodology for assessing eco-efficiency in logistics networks.

Quariguasi Frota Neto et al. (2008) reviewed the main activities influencing sustainability in logistics networks and developed a framework for the design and evaluation of sustainable logistics networks, in which profitability and environmental impacts are balanced. The technique was based on the commonalities between DEA and multi-objective programming. They illustrated the approach in the European pulp and paper sector.

To sum up the brief review of the literature on DEA in logistics, DEA proved to be a reliable, flexible and efficient tool for measuring the performance of both supply chain members and the entire supply chain systems. However, because of unavailability of data in many organisations, the complex considerations of supply chains are impossible and necessarily limited to the context of direct relationships of selected tiers of the supply chain and its members.

\section{COURIER AND MESSENGER COMPANIES IN POLAND}

The sector of couriers and messengers in Poland is growing very rapidly. In 2014, courier companies provided 171.61 million of units of service and achieved the revenue of PLN 2462.65 million. For comparison, 2013 saw 132.46 million of units of service provided and PLN 2176.12 million in revenues earned. That gives an increase of $29.5 \%$ in terms of the volume and $13.1 \%$ in terms of the revenue. The development of the courier sector is linked to the market of e-commerce, which in Poland continues to remain at the early stages of expansion if compared to the level of e-commerce in the Western Europe despite its rapid growth that has been taking place for some years (Report..., 2014; Report..., 2013).

There are approaches to assess courier companies in Poland using the DEA, for example Kozłowska (2014) but the reliability of the comparison can be questioned due to arbitrary rather than a homogeneous set of data, including companies with a different core business, despite the same PKD (Polish Classifi- 
cation of Activity) number. First at all, nine service providers of the courier sector in 2014, the largest in terms of volume and revenue, had the share of $84.63 \%$ of the total volume and the share of $94.62 \%$ of the total revenue generated from the provision of courier services (Report..., 2014). Table 1 provides their total operating revenue.

Tab. 1. Leaders in the courier segment in 2014

\begin{tabular}{|l|l|l|c|}
\hline \multicolumn{1}{|c|}{ Company NAME } & \multicolumn{1}{|c|}{ ABbreV. } & $\begin{array}{c}\text { Total OPERATING } \\
\text { ReVENUE } \\
\text { [MLN PLN] }\end{array}$ \\
\hline 1. & DHL Express (Polska) sp. z o.o. & DHL & 1298.6 \\
\hline 2. & DPD Polska sp. z o.o. & DPD & 690.5 \\
\hline 3. & FedEx Express Polska sp. z o.o. & FedEx & 249.8 \\
\hline 4. & Federal Express Poland sp. z o.o. & Federal & 96.9 \\
\hline 5. & General Logistics Systems Poland sp. z o.o. & GSL & 378.8 \\
\hline 6. & K-EX sp. z o.o. & K-EX & 140.7 \\
\hline 7. & Siódemka S.A. & Siódemka & 337.9 \\
\hline 8. & TNT Express Worldwide 'Poland' sp. z o.o. & TNT & 429.6 \\
\hline 9. & UPS Polska sp. z o.o. & UPS & 1540.4 \\
\hline
\end{tabular}

Source: on the basis of (Report..., 2014; EMIS).

It is worthwhile mentioning that the market of couriers and messengers is highly dynamic. Mergers and acquisitions are also rather frequent. In 2012, FedEx bought the Polish Opek Sp. z o.o. In 2014, DPD Polska, which is owned by the French State Mail, bought Siódemka. In 2015, FedEx planned to take over TNT Express. For the analysis, the data about courier companies was collected from Emerging Markets Information Service (EMIS) database.

Traditionally, a courier is associated with the part of the delivery system that connects a retailer and a customer. However, in 2012, every third company in the European Union had something to do with electronic shopping. Polish companies exceeded the thresholds of $20 \%$ but ranked far below the EU average. In 2013, compared to the previous year, the percentage of firms ordering goods and services via computer networks increased by 2.4 percentage points and amounted 23.6\%. Electronic commerce became the most popular among big companies involved in computer and communication equipment repairs as well as information and communication (The information society ..., 2014). However, services provided by external couriers mostly form the basis of logistic systems used by micro and small enterprises. The hypothetical system that consists of two members, i.e. a courier and another enterprise, is the subject of the analysis presented in this paper.

\section{RESEARCH METHOD FOR EVALU- ATING COURIER AND MESSENGER COMPANIES}

Firstly, the traditional DEA model to measure the relative performance of courier companies was applied. The analysed process included transforming two inputs in the form of a payroll plus social security and other benefits as a measure of labour costs and other operating expenses into output - the total operating revenue (Fig. 1). In the opinion of the author, labour costs are a better reflection of labour use in a company rather than the number of employees, even if converted into full-time jobs. Labour productivity determined by the level of employment only partially expresses the personal abilities of employees and the intensity of their effort. Rather, it reflects how effectively their work is combined with other input factors in the production process. The chosen solution, to a greater extent, reflects the degree of the use of available resources and qualifications of employees. Still, the solution has some flaws. First at all, it is a derivative of the local labour market conditions and is associated with regional differentiation of salaries. Moreover, it contains additional costs, such as severance pays for dismissed employees, which are not directly associated with processes of the production/ services.

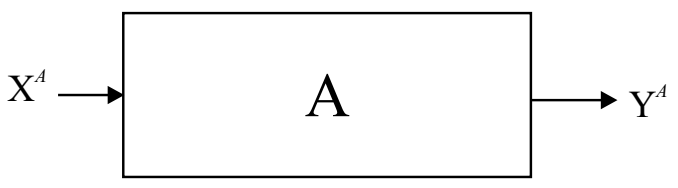

where:

- $\mathrm{X}^{A}=\left(x_{1}^{A}, x_{2}^{A}\right)$,

- $\quad x_{1}^{A}$ - payroll plus social security and other

benefits,

- $\quad x_{2}^{A}$ - other operating expenses,

- $\quad \mathrm{Y}^{A}=\left(y_{1}^{A}\right)$,

- $\quad y_{1}^{A}$ - total operating revenue.

Fig. 1. One-stage DEA evaluation of a courier company 
The efficiency in one stage DEA was obtained by employing the conventional DEA CCR-I model:

$$
\begin{aligned}
& \Omega_{A}^{*}=\min _{\Omega_{A}, \lambda_{j}} \Omega_{A} \\
& \sum_{j=1}^{J} \lambda_{j} x_{i j}^{A} \leq \Omega_{A} x_{i j_{O}}^{A} \quad i=1,2, \ldots, I^{A} \\
& \sum_{j=1}^{J} \lambda_{j} y_{t j}^{A} \geq y_{t j_{O}}^{A} \quad t=1, \ldots, T \\
& \lambda_{j} \geq 0, \quad j=1, \ldots, J
\end{aligned}
$$

where:

- $\quad x_{i j}^{A}-i$-th input for the $\mathrm{DMU}_{j}$,

- $y_{t j}^{A}-t$-th output for the $\mathrm{DMU}_{j}$,

- $j=1, \ldots, J$ - number of DMUs,

- $\lambda_{j}$ - weighs.

Such approach would be appropriate and sufficient in the case of analysing and identifying the best practice among courier enterprises. When evaluating

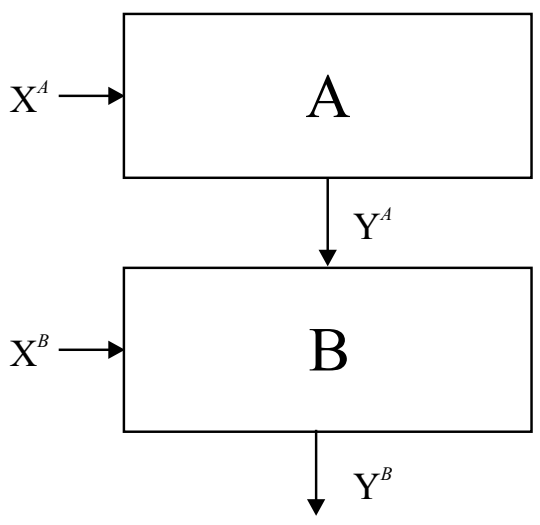

where:

- $\mathrm{X}^{A}=\left(x_{1}^{A}, x_{2}^{A}\right)-$ direct input vector

of the courier,

- $x_{1}^{A}$ - payroll plus social security,

- $x_{2}^{A}$ - other operating expenses,

- $\quad \mathrm{Y}^{A}=\left(y_{1}^{A}\right)$ - intermediate output vector of the courier/input vector of the other enterprise,

- $y_{1}^{A}$ - total operating revenue,

- $\left.\mathrm{X}^{B}=\left(x_{1}^{B}, x_{2}^{B}\right)\right)$ - direct inputs to the other enterprise,

- $\quad x_{1}^{B}$ - payroll plus social security,

- $x_{2}^{B}$ - other operating expenses,

- $\quad \mathrm{Y}^{B}=\left(y_{1}^{B}\right)$ - direct output vector of the other enterprise,

- $y_{1}^{B}$ - profit.

Fig. 2. Two-stage network DEA model for evaluating courier and other enterprises network processes, the outputs from one stage become the inputs of the next stage and other inputs can enter the process at each intermediate stage. Moreover, there usually is a conflict between chain members' interests. First member's objective to maximise, for example, the revenue can at the same time be the minimisation of costs for the next member. In order to evaluate courier and messenger companies, the following model presented in Fig. 2 was applied.

Presented in Fig. 2, the two-stage network structure with additional inputs to the second stage can be estimate by following equations adopted from $\mathrm{Zhu}$ (2003):

$$
\begin{aligned}
& \Omega^{*}=\min _{\Omega_{A}, \Omega_{B}, \lambda_{j}, \beta_{j}, \tilde{z}}\left(\Omega_{A}+\Omega_{B}\right) / 2 \\
& \sum_{j=1}^{J} \lambda_{j} x_{i j}^{A} \leq \Omega_{A} x_{i j_{O}}^{A} \quad i=1,2, \ldots, I^{A} \\
& \sum_{j=1}^{J} \lambda_{j} z_{t j}^{A-B} \geq \tilde{z}_{t j o}^{A-B} \quad t=1, \ldots, T \\
& \lambda_{j} \geq 0, j=1, \ldots, J \\
& \sum_{j=1}^{J} \beta_{j} x_{i j}^{B} \leq \Omega_{B} x_{i j_{O}}^{B} \quad i=1,2, \ldots, I^{B} \\
& \sum_{j=1}^{J} \beta_{j} y_{r j}^{B} \geq y_{r j_{O}}^{B} \quad r=1,2, \ldots, R^{B} \\
& \sum_{j=1}^{J} \beta_{j} z_{t j}^{A-B} \leq \tilde{z}_{t j_{O}}^{A-B} t=1, \ldots, T \\
& \beta_{j} \geq 0, j=1, \ldots, J \\
& \Omega_{A}, \Omega_{B} \leq 1
\end{aligned}
$$

where:

- $\quad x_{i j}^{A}-i$-th input to the A stage for the DMUj,

- $\quad x_{i j}^{B}-i$-th input to the B stage for the DMUj,

- $z_{t j}^{A-B}-t$-th intermediate output from $\mathrm{A}$ to enterprise $B$ (input to $B$ ),

- $\quad y_{r j}^{B}-r$-th output to the B stage for the $\mathrm{DMU} j$,

- $j=1, \ldots, J$ - number of DMUs,

- $\Omega^{*}=1$ means that there exists an optimal solution such as $\lambda_{j_{o}}^{*}=\beta_{j_{o}}^{*}=1$.

The model (2) integrates the efficiency of each stage in the network via geometric averages. In the article, the models to obtain the efficiency scores were solved in Microsoft Excel, using VBA programming to automate it.

Figs. 3 and 4 illustrate potential extensions of the presented and empirically applied two-stage model.

The basic two-stage DEA model can be simply extended to the structure: producer-courier-another enterprise, as shown in Fig. 3. The interesting approach Liang et al. (2011) is the proposal to include the feedback to the serial network process. Fig. 4 presents the situation where the output from the second stage can be fed back as the input to the first stage.

Since DEA is a non-parametric method, changes in the data set may highly affect the final results. The reliability of DEA scores can be measured alter- 


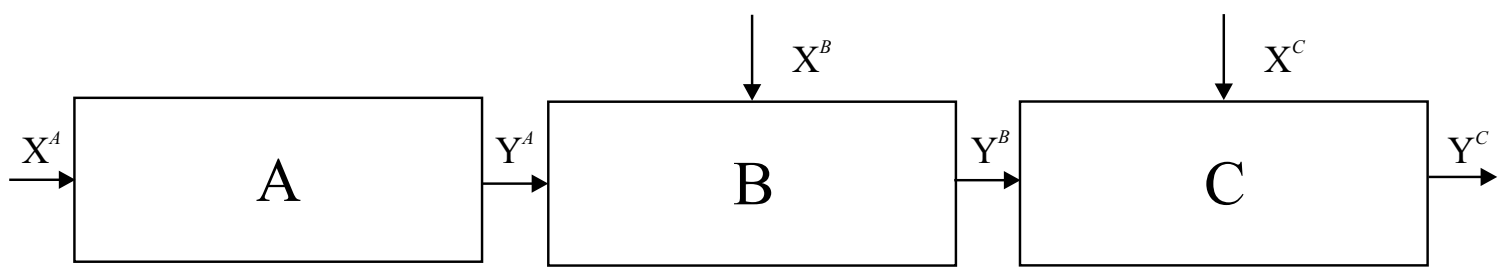

Fig. 3. Tree-stage process

Source: adopted on the basis of (Cook \& Zhu, 2014).

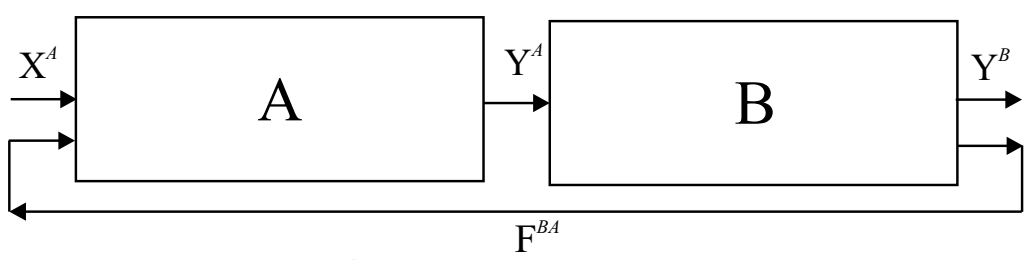

Fig. 4. Two-stage process with feedback

Source: adopted on the basis of (Cook \& Zhu, 2014).

natively by the bootstrap technique or jack-knife procedure. In this work, because the sample set is small, the author proposes examining the sensitivity of DEA efficiency scores by the jack-knife procedure. Jack-knife is a resampling method that uses a subset of available data. The procedure involves the repetition dropping one DMU and using the remaining data to compute DEA scores. To test the robustness of DEA by jack-knife, it is enough to exclude only efficient units. The standard deviation of obtained efficiency scores provides information, for example, on the presence of outliers.

\section{RESULT}

The data about the courier companies for the analysis was collected from EMIS database. The hypothetical chain that consists of two types of members, i.e. leaders of the sector, is listed in Tab. 1. The bigger enterprise in the electronic shopping sector, that does not have stationary shops (Bonprix Sp. z o.o.) and has fixed values of profit of 56.89, operating expenses of 614.82 and the payroll of PLN $16628 \mathrm{mln}$ was the subject of analysis of this paper. Efficiency ratios relating to courier companies that evaluate how they transform operating costs to revenue and efficiency ratios relating to courier companies as members of chains differ significantly (Tab. 2). The efficiency of the second member of the chain (another company) was equal to one due to assumptions of the fixed values. The frontier plot and selected inputs and outputs of courier companies included in DEA are illustrated in Fig. 5.
Tab. 2. DEA scores

\begin{tabular}{|l|c|c|c|}
\hline & $\begin{array}{c}\mathbf{\Omega}^{*}{ }_{A} \\
\text { (ONE-STAGE } \\
\text { COURIER } \\
\text { EFFICIENCY) }\end{array}$ & $\begin{array}{c}\mathbf{\Omega}^{*} \\
\text { (TWO-STAGE } \\
\text { PROCESS } \\
\text { EFFICIENCY) }\end{array}$ & $\begin{array}{c}\mathbf{\Omega}_{A} \\
\text { (COURIER EFFI- } \\
\text { CIENCY IN TWO- } \\
\text { STAGE PROCESS) }\end{array}$ \\
\hline DHL & 0.853 & 0.532 & 0.064 \\
\hline DPD & 0.920 & 0.565 & 0.129 \\
\hline FedEx & 0.777 & 0.651 & 0.301 \\
\hline Federal & 0.724 & 0.862 & 0.724 \\
\hline GSL & 1.000 & 0.628 & 0.256 \\
\hline K-EX & 0.782 & 0.769 & 0.538 \\
\hline Siódemka & 0.965 & 0.638 & 0.277 \\
\hline TNT & 0.961 & 0.608 & 0.217 \\
\hline UPS & 1.000 & 0.531 & 0.063 \\
\hline
\end{tabular}

While analysing the efficiency of courier and messenger sector, it can be said that the average efficiency equals to 0.88 and is highly prevalent among the leaders of the sector. Additionally, it can be noticed that this set is highly homogeneous. Two companies are fully efficient: GSL and UPS. Not fully efficient companies should reduce their payroll (from the range of 0 to $45 \%$ ) or/and increase their revenue (from $0 \%$ to $38 \%$ ). In other words, compared to the best, there is the surplus in spending and deficits in results and, thus, it is possible to improve the efficiency. The evaluation of the systems (courier another enterprise), where the outputs from one stage become the inputs of the next stage and other inputs are entered, is not as positive. The resulting scores are lower and vary between objects from 0.53 to 0.86 .

It is obvious that improvements of individual chain members do not lead to the improvement of the chain as a whole. The compatibility of the ranking of 


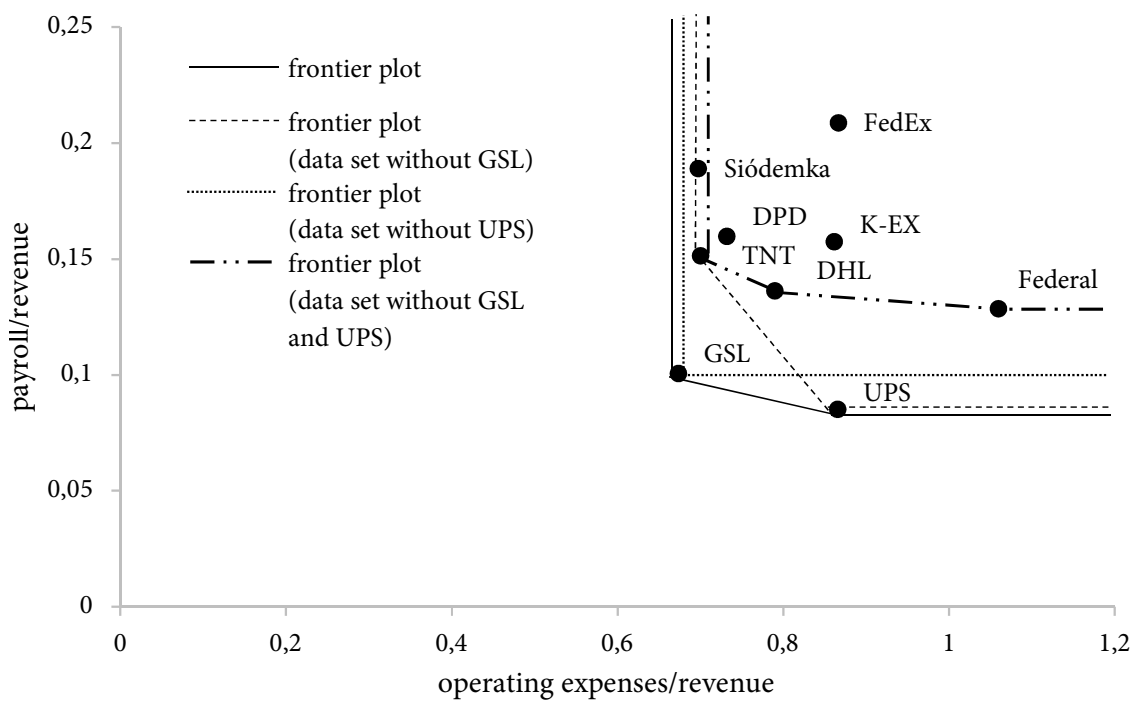

Fig. 5. CCR DEA model for couriers companies - the frontier plot

courier companies and ranking of the analysed chain is -0.64 , as measured by the Spearman rank correlation.

The jack-knife procedure for checking the stability of the results that involve the exclusion of the efficient units moved the frontier, which could have been expected, and improved the average efficiencies. The new alternative efficiency frontiers are illustrated in Fig. 5. Detailed numerical results are presented in Table 3. Table 3 also summarises the results of the evaluations of the system in the case of removal of efficient units. All calculations were made in Microsoft Excel using Solver Add-in.
Implemented jack-knife procedure resulted in very slight changes, of course, on the positive side. Assessing the market of courier leaders with the exception of the best, resulted in the emergence of new leaders. This time they were: Siódemka, TNT and Federal. Similarly, the assessment of the designed logistics system also showed a surprising lack of sensitivity to the modification of the analysed set. In summary, a very limited assessment of courier and messenger companies using the DEA method seems to be a valuable alternative to the conventional analysis based only on financial indicators. The reliable, accurate evaluation of individual system components as well as the overall system should be the basis for

Tab. 3. DEA scores after the jack-knife procedure

\begin{tabular}{|l|c|c|c|c|c|c|c|c|c|c|}
\hline \multicolumn{1}{|c|}{ CCR-I } & \multicolumn{3}{c|}{ (ONE STAGE COURIER EFFICITCY) } & \multicolumn{3}{c|}{ (TWO STAGE PROCESS EFFICIENCY) } \\
\hline UNIT NAME & ALL & $\begin{array}{c}\text { WITHOUT } \\
\text { GSL }\end{array}$ & $\begin{array}{c}\text { WITHOUT } \\
\text { UPS }\end{array}$ & $\begin{array}{c}\text { WITHOUT } \\
\text { GSL AND } \\
\text { UPS }\end{array}$ & AVERAGE & ALL & $\begin{array}{c}\text { WITHOUT } \\
\text { GSL }\end{array}$ & $\begin{array}{c}\text { WITHOUT } \\
\text { UPS }\end{array}$ & $\begin{array}{c}\text { WITHOUT } \\
\text { GSL AND } \\
\text { UPS }\end{array}$ & $\begin{array}{c}\text { AVERAGE } \\
\text { DHL }\end{array}$ \\
\hline DPD & 0.85 & 0.95 & 0.85 & 1.00 & 0.92 & 0.53 & 0.54 & 0.53 & 0.54 & 0.53 \\
\hline FedEx & 0.92 & 0.96 & 0.92 & 0.96 & 0.94 & 0.57 & 0.57 & 0.56 & 0.57 & 0.57 \\
\hline Federal & 0.78 & 0.81 & 0.78 & 0.81 & 0.79 & 0.65 & 0.66 & 0.65 & 0.66 & 0.65 \\
\hline GSL & 0.72 & 0.78 & 0.78 & 1.00 & 0.82 & 0.86 & 0.89 & 0.89 & 1.00 & 0.91 \\
\hline K-EX & 1.00 & & 1.00 & & 1.00 & 0.63 & & 0.63 & & 0.63 \\
\hline Siódemka & 0.78 & 0.86 & 0.78 & 0.89 & 0.83 & 0.77 & 0.80 & 0.77 & 0.81 & 0.78 \\
\hline TNT & 0.97 & 1.00 & 0.97 & 1.00 & 0.98 & 0.64 & 0.64 & 0.64 & 0.64 & 0.64 \\
\hline UPS & 0.96 & 1.00 & 0.96 & 1.00 & 0.98 & 0.61 & 0.61 & 0.61 & 0.61 & 0.61 \\
\hline & 1.00 & 1.00 & & & 1.00 & 0.53 & 0.53 & & & 0.53 \\
\hline Average & & & & & & & & & & \\
\hline
\end{tabular}


managerial decision-making. Especially in the face of customer expectations conflicting with the pressure to earn profit. In the article, due to the hypothetical nature of the relationship, the derivation of conclusions and implications was abandoned.

\section{CONCLUSIONS}

Self-service transport and forwarding or the engagement of specialised external companies are questions asked by an increasing number of small, medium and large companies. This article does not provide answers on the best business model. It only shows and discusses an alternative, compared to traditional financial indicators, which is an approach for the assessment of the efficiency of courier companies. In contrast to the traditional performance measurement, which uses sets of single indicators and compares one output to one resource, DEA considers simultaneously multiple inputs and outputs that are correlated. The key issue is the selection of appropriate input and output variables. The article takes into account such indicators as: operating expenses, payroll plus social security, total operating revenue and payroll, operating expenses and profit of the company using the services of couriers. This choice of indicators was related to the availability of data. However, it is worth noting that in addition to the price of services translated into the cost/profit in the logistics system, an increasing popularity is gained criteria, such as the quality treated as the reliability, speed, delivery in a specific, narrow range of time, IT innovations that enable the monitoring and modification of the delivery on any stage of service or complexity of services, including, for example, packaging. Increasingly more attention is given to such issues as ecology in the transport sector and not only the $\mathrm{CO}_{2}$ emissions but also organic and recyclable packaging.

DEA can be used in each case to evaluate DMUs on any selected criteria. The only limitation is the availability of relevant data describing the set. While selecting the criteria analysis, it should not be forgotten that it should be based on a thorough understanding of the fundamental economics relations.

\section{ACKNOWLEDGEMENTS}

The research was conducted within S/WZ/1/2014 project and was financed from Ministry of Science and Higher Education funds.

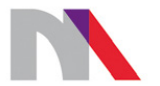

\section{Ministry of Science and Higher Education}

Republic of Poland

7th International Conference on Engineering, Project, and Production Management (EPPM2016) was financed in the framework of the contract no. 712/P-DUN/2016 by the Ministry of Science and Higher Education from the funds earmarked for the public understanding of science initiatives.

7th International Conference on Engineering, Project, and Production Management (EPPM2016) finansowana w ramach umowy 712/P-DUN/2016 ze środków Ministra Nauki i Szkolnictwa Wyższego przeznaczonych na działalność upowszechniającą naukę.

\section{LITERATURE}

Chen, C., \& Yan, H. (2011). Network DEA model for supply chain performance evaluation. European Journal of Operational Research, 213(1), 147-155. doi: 10.1016/j. ejor.2011.03.010

Chen, Y., Liang, L., \& Yang, F. (2006). A DEA game model approach to supply chain efficiency. Annals of Operations Research, 145(1), 5-13. doi: 10.1007/s10479006-0022-y

Cook, W. D., \& Zhu, J. (Ed.). (2014). Data Envelopment Analysis: A Handbook of Modeling Internal Structure and Network. Springer.

Färe, R., \& Grosskopf, S. (2000). Network DEA. Socio-Economic Planning Sciences, 34(1), 35-49.

Główny Urząd Statystyczny [Central Statistical Office of Poland]. (2014). Społeczeństwo informacyjne $w$ Polsce. Wyniki badań statystycznych lat 2010-2014 [The information society in Poland. Statistical results of years 2010-2014]. Retrieved from http://stat.gov.pl/ obszary-tematyczne/nauka-i-technika-spoleczenstwo-informacyjne/spoleczenstwo-informacyjne

Johnson, A., \& Mcginnis, L. (2011). Performance measurement in the warehousing industry. IIE Transactions, 43, 220-230. doi: 10.1080/0740817X.2010.491497

Kao, C. (2014). Network data envelopment analysis: A review. European Journal of Operational Research, 239, 1-16. doi: 10.1016/j.ejor.2014.02.039

Kozłowska, J. (2014). Technical efficiency of Polish companies operating in the couriers and messengers sector - the application of data envelopment analysis method. Quantitative Methods in Economics, XV(2), 339-348.

Lewis, H. F., \& Sexton, T. R. (2004). Network DEA: efficiency analysis of organizations with complex internal structure. Computers \& Operations Research, 31, 1365-1410. doi:10.1016/S0305-0548(03)00095-9 
Liang L., Yang F., Cook W. D., \& Zhu J. (2006). Data EA models for supply chain efficiency evaluation. Annals of Operations Research, 145(1), 35-49. doi 10.1007/ s10479-006-0026-7

Liang, L., Li Z. Q., Cook, W. D, \& Zhu, J. (2011). Data envelopment analysis efficiency in two stage networks with feedback. IIE Transactions, 43(5), 309-322. doi:10.1080/0740817X.2010.509307

Lu, B., \& Wang, X. L. (2012). Comparative Studies on Efficiency Evaluation of Chinese and Korean Major Container Terminals. Advances in information Sciences and Service Sciences (AISS), 4(23). doi: 10.4156/ AISS

Mentzer, J. T., DeWitt, W., Keebler, J. S., Soonhoong, M., Nix, N. W., Smith, C. D., \& Zacharia, Z. G. (2001). Defining Supply Chain Management. Journal of Business Logistics, 22(2), 1-25. doi: 10.1002/j.2158-1592. 2001.tb00001.x

Min, H., \& Joo, S. J. (2006). Benchmarking the operational efficiency of third party logistics providers using data envelopment analysis. Supply Chain Management: An International Journal, 11(3), 259-265.

Mishra, R. K. (2012). Measuring supply chain efficiency: A DEA approach. Journal of Operations and Supply Chain Management, 5(1), 45-68.

Momeni, E., Tavana, M., Mirzagoltabar, H., \& Mirhedayatian, S. M. (2014). A new fuzzy network slacks-based DEA model for evaluating performance of supply chains with reverse logistics. Journal of Intelligent \& Fuzzy Systems, 27, 793-804. doi: 10.3233/IFS131037

Quariguasi Frota Neto, J., Bloemhof-Ruwaard, J. M., van Nunen, J. A. E. E., \& van Heck, E. (2008). Designing and evaluating sustainable logistics networks. International Journal Production Economics, 111, 195-208. doi: 10.1016/j.ijpe.2006.10.014

Urząd Komunikacji Elektronicznej [Office of Electronic Communications]. (2015). Report on the state of the postal market in 2014. Retrieved from https://en.uke. gov.pl/files/?id_plik=20239

Urząd Komunikacji Elektronicznej [Office of Electronic Communications]. (2014). Report on the state of the postal market in 2013. Retrieved from https://en.uke. gov.pl/files/?id_plik=17039

Wong, P. W., \& Wong, K. Y. (2007). Supply chain performance, measurement system using DEA modeling. International Journal of Management and Data System, 107(3), 361-381. doi: 10.1108/0263557071073 4271

Zhu, J. (2003). Quantitative models for performance evaluation and benchmarking: data envelopment analysis with spreadsheets and DEA Excel Solver. Boston: Kluwer Academic Publishers. 